\title{
LXXIX. Theorems for calculating the Temperaments of such regular douzeaves as are commensurable, or defined by a certain number of equal parts, into which the Octave is divided
}

John Farey Sen.

To cite this article: John Farey Sen. (1811) LXXIX. Theorems for calculating the Temperaments of such regular douzeaves as are commensurable, or defined by a certain number of equal parts, into which the Octave is divided, Philosophical Magazine Series 1, 38:164, 434-436, DOI: $10.1080 / 14786441108638683$

To link to this article: http://dx.doi.org/10.1080/14786441108638683

央 Published online: 27 Jul 2009.

Submit your article to this journal ¿

Џ Article views: 2

Q View related articles ¿ 
The attempts which $I$ have made to bleach the wax have been conducted on a small scale; but from the experiments related it appears that, after the colour has been changed by the action of very dilute nitric acid, it may be rendered nearly white by the usual means. I have not had sufficient time to ascertain whether the wax can be more effectually bleached by long continued exposure, nor bave I had an opportunity of submitting it to the processes employed by the bleachers of bees wax.

Perhaps the most important part of the present inquiry is that which relates to the combustion of the vegetable wax in the form of candles.

The trials which have been made to ascertain its fitness for this purpose are extremely satisfactory; and when the wick is properly proportioned to the size of the eandle, the combustion is as perfect and uniform as that of commors bees wax.

The addition of from one-eighth to one-tenth part of tallow is sufficient to obviate the brittleness of the wax in its pure state, without giving it any unpleasant smell, or materially impairing the brilliancy of its flame. A mixture of three parts of the vegetable wax with one part of bees wax also makes very excellent candles.

LXXIX. Theorems for calculating the Temperaments of such regular Douzeaves as are commensurable, or defined by a certain Number of equal Parts, into which the Octave is divided. By John Farey, Sen.

\section{To Mr. Tilloch.}

Sir, $H_{\text {aving been applied to by a musical friend, to point }}$ out the method of calculating the Temperament of the Fifths, in any given commensurable system of Musical Intervals, without reference to the Memoirs of the Academy of Sciences (a work which many have not the opportunity of consulting) as is done in the 1st, and several others of the Scholia to my Six Musical Theorems in your 36 th volume, p.45; I beg the favour of you to give a place to the following Observations and Theorems on Commensurable Systems.

It is well known, that merely giving the number of equal parts into which the octave is to be divided, is not sufficient to define, in all cases, the regular douzeave that results, or system wherein all the Fifths to a given extent are alike tempered; the common property of which is, as Dr. 
Smith has shown, in his truly excellent "Harmonics," Prop. III, and XVIII, that the sum of 5 of the mean Tones $(T)$ and two of the major Limmas (L) are equal to the Octave, in all such systems. Thus in the system of $M$. Henfling (Schol. X. p. 50) wherein the Octave is divided into 50 equal parts, six different sets of $T$ and $L$ may be found to answer the above condition, viz.

$\begin{array}{rl}\mathrm{T} & \mathrm{L} \\ 5 \times 10+2 \times \mathrm{O} & =50 \\ 5 \times 8+2 \times 5 & =50 \\ 5 \times 6+2 \times 10 & =50 \\ 5 \times 4+2 \times 15 & =50 \\ 5 \times 2+2 \times 20 & =50 \\ 5 \times 0+2 \times 25 & =50\end{array}$

Which sets of answers may, in general, be obtained by this rule, viz.

From the given number of equal parts in the Octave $(a)$, deduct successively the even numbers in the series $0, \boldsymbol{2}, \mathbf{4}$, $6,8, \&$ c. until a remainder is found, divisible by 5 , or which ends with 0 or 5 , and let such even subtrahend be called $b$ : then will $\frac{a-b}{5}$ be the greatest value of $T$, and $\frac{b}{2}$ the least or corresponding value of $\mathrm{L}$; and all the other corresponding values of $T$ will decrease from this by 2 , and those of $\mathbf{L}$ increase by 5 , in succession, as in the example above. It will however be unnecessary, to carry this process on any further, than till $\mathrm{L}$ becomes equal to $\mathrm{T}$; since in all practical systems, the value of $\mathrm{L}$ cannot differ very greatly from the half of $T$, and thus the second line in the above example, is the only practical system that results from a division of the Octave into 50 equal parts; and so of any other value of $a$.

In practice therefore, the value of $b$ (or $2 \mathrm{~L}$ ) will be restricted to some of those even subtrahends that produce practical systems, and which may be determined, in my new notation, by

Theorem 7. $-r=\frac{b}{a} \times 61.421264 \Sigma-9.23622212 \Sigma$, the fiat temperament of the Fifths, in the system having $a$ equal parts in the Octave.

Or, in reciprocals of common logarithms, by

Theor. 8. $-r=\frac{b}{a} \times \cdot 0301029,99566-0045267,3834$.

For example, in Mercator's System, mentioned in Schol. 1, $a=53$ and $b=8$, and we have $8 \times 61.421264 \div 53$ $-9.236222=-.03491121 \Sigma$ the flat Temperament of the E e 2 
436 The Originality of Daniel's Life-Preserver disputed.

Fifth : and in the other Scholia, we have for the Commensurable Systems mentioned, as follows, viz.

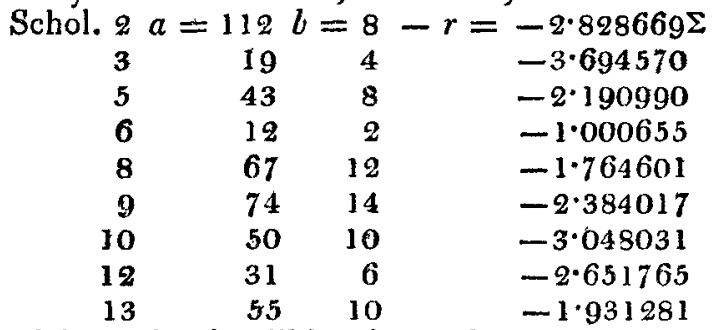

Which results, it will be observed, are much more exact than those which I before gave, owiug to too few places of decimals having been used, as my able friend, the Rev. C.J. Smyth, long ago pointed out to me, after recalculating end enlarging M. Sauveur's Table of Commensurable Systems, and which it were much to be wished that he would publish.

The Temperament of the Fifth or $-r$ being thus obtained, for any Commensurable System, we have only to consider $s$ as $=1,-t=0$, and $u=1$, and all the other Temperaments and the Wolves of any such system will readily be obtained from the Theorems at page 41 of the 36 th volume, or from the Corollaries that follow at page 371 .

If we select the 6th Scholium as an example of the use of Theorem 8, we have $\frac{b}{a}=\frac{2}{12}=\frac{1}{6}$, and 0301029,9957 $\div 6-0045267,3834=0004904,2825=-r$, the reciprocal logarithm of the flat temperament of the Isotonic System : from which if we take $\cdot 0004901,07 \mathrm{~J}$ t the reciprocal logarithm of $\Sigma$, we have 3.2112 (or $\frac{1}{12}$ of 38,5342 the reciprocal logarithm of $m$ ), or $\Sigma+\frac{1}{2} m$, as the proper flattening of the Equal Temperament.

Allow me here to correct two errata in the 5 th Scholium, p. 46, of volume $x \times x$ vi. bottom line and line 6 from the bottom, for flat read sharp.

$$
\begin{gathered}
\text { I am, sir, } \\
\text { Your obedient servant, } \\
\begin{array}{c}
\text { Upper Crown Street, } \\
\text { Dec. 4, 181 l. }
\end{array} \\
\text { JohN FAREY, Sen. }
\end{gathered}
$$

LXXX. The Originality of Daniel's Life-Preserver disputed.

$$
\text { To Mr. Tilloch. }
$$

SIR, $T_{\text {HE advantages that have accrued to the public, from }}$ the institution of the Society for the Encouragement of Arts and 